\title{
Polycystic ovary syndrome: a common reproductive syndrome with long-term metabolic consequences
}

\author{
Tiffany TL Yau, Noel YH Ng, LP Cheung, Ronald CW Ma *
}

This article was published on $24 \mathrm{Nov}$ 2017 at www.hkmj.org.

\section{A B S T R A C T}

Polycystic ovary syndrome is the most common endocrine disorder among women of reproductive age. Although traditionally viewed as a reproductive disorder, there is increasing appreciation that it is associated with significantly increased risk of cardiometabolic disorders. Women with polycystic ovary syndrome may present to clinicians via a variety of different routes and symptoms. Although the impact on reproduction predominates during the reproductive years, the increased cardiometabolic problems are likely to become more important at later stages of the life course. Women with polycystic ovary syndrome have an approximately 2 - to 5 -fold increased risk of dysglycaemia or type 2 diabetes, and hence regular screening with oral glucose tolerance test is warranted. Although the diagnostic criteria for polycystic ovary syndrome are still evolving and are undergoing revision, the diagnosis is increasingly focused on the presence of hyperandrogenism, with the significance of polycystic ovarian morphology in the absence of associated hyperandrogenism or anovulation remaining uncertain. The management of women with polycystic ovary syndrome should focus on the specific needs of the individual, and may change according to different stages of the life course. In view of the clinical manifestations of the condition, there is recent debate about whether the current name is misleading, and whether the condition should be renamed as metabolic reproductive syndrome.

\section{Hong Kong Med J 2017;23:622-34}

DOI: $10.12809 / \mathrm{hkmj} 176308$

${ }^{1}$ TTL Yau \#, FHKCP, FHKAM (Medicine)

${ }^{1} \mathrm{NYH} \mathrm{Ng}{ }^{\#}, \mathrm{BSc}$, MRes

${ }^{2}$ LP Cheung, FRCOG, FHKAM (Obstetrics and Gynaecology)

1,3 RCW Ma *, FRCP, FHKAM (Medicine)

\# TT Yau and NY Ng have equal contribution in this study.

1 Department of Medicine and Therapeutics, The Chinese University of Hong Kong, Shatin, Hong Kong

2 Department of Obstetrics and Gynaecology, The Chinese University of Hong Kong, Prince of Wales Hospital, Shatin, Hong Kong

Hong Kong Institute of Diabetes and Obesity, The Chinese University of Hong Kong, Shatin, Hong Kong

* Corresponding author: rcwma@cuhk.edu.hk

\section{Introduction}

Polycystic ovary syndrome (PCOS) was first described by Stein and Leventhal in $1935,{ }^{1}$ when they noted an association between the presence of bilateral polycystic ovaries and signs of amenorrhoea, oligomenorrhoea, hirsutism, and obesity. It is now recognised as one of the most common endocrine disorders of women, affecting between $6 \%$ and $12 \%$ of women overall. ${ }^{2}$ A study in southern Chinese reported a prevalence of $2.2 \%$ among women of reproductive age. ${ }^{3}$ The prevalence can be as high as $70 \%$ to $80 \%$ in women with oligoamenorrhoea and $60 \%$ to $70 \%$ in women with anovulatory infertility. Women with PCOS have an increased risk of gynaecological, reproductive, medical and sleep problems, and hence are at risk of increased morbidities across the life course (Fig 1). ${ }^{4}$ Despite being a common condition, however, the presenting features of PCOS are often not recognised, resulting in a delay in diagnosis. In a recent international survey, approximately half of the women with PCOS consulted three or more health care providers before the diagnosis was made, and more than one third experienced a diagnostic delay in excess of 2 years. ${ }^{5}$

\section{Diagnosis of polycystic ovary syndrome: historical aspects and evolution of diagnostic criteria}

Polycystic ovary syndrome is considered to be a heterogeneous disorder with multifactorial cause. The principal features of PCOS include hyperandrogenism, oligomenorrhoea, and/or polycystic ovaries. There have been several proposed diagnostic criteria for PCOS as described in Table $1 .^{6-9}$ All criteria require exclusion of other disorders that may mimic the clinical features of PCOS, such as thyroid dysfunction, hyperprolactinaemia, nonclassic congenital adrenal hyperplasia $(\mathrm{CAH})$, and Cushing's syndrome.

The prevalence of PCOS depends on the diagnostic criteria used to define the disorder. To date, the prevalence of PCOS has been determined primarily using the National Institutes of Health 1990 criteria. A summary report from the National Institutes of Health Evidence-based Methodology Workshop on PCOS in December 2012 concluded 
that the Rotterdam criteria should be adopted for now because it is the most inclusive. ${ }^{10}$ Using the Rotterdam criteria, many patients can be diagnosed based on the history and physical examination (eg a history of irregular menses, and clinical signs of hyperandrogenism). The panel also suggested that the disorder should be renamed to more adequately reflect the complex metabolic, hypothalamic, pituitary, ovarian, and adrenal interactions that characterise the syndrome. A previous local study by Lam et $\mathrm{al}^{11}$ comparing the different diagnostic criteria in Hong Kong Chinese women concluded that the Rotterdam criteria are generally applicable to our population. Nevertheless, recent discussion has centred on the importance of hyperandrogenism, and emerging evidence suggests that women with radiological evidence of polycystic ovaries, but no other clinical features of PCOS, represent a population generally of lower risk who are distinct from other women with PCOS who fulfil current diagnostic criteria. ${ }^{12}$

\section{Pathogenesis}

To date, the pathophysiology of PCOS remains unclear; yet, substantial evidence suggests it is a multifactorial condition, where interactions between endocrine, metabolic, genetic, and environmental factors intrinsic to each other act in consonance towards a common result (Fig 2). ${ }^{13,14}$ Also, the heterogeneity of PCOS further reinforces its multifactorial nature. Although familial segregation of cases suggests a genetic component in this syndrome, most of the susceptibility genes and single-nucleotide polymorphisms remain to be discovered. ${ }^{15,16}$ Among its diverse phenotypes, hyperandrogenism and ovarian dysfunction are recognised as the two main features of PCOS. ${ }^{6,16}$ Hyperandrogenism in PCOS is recognised as the excessive androgen biosynthesis, use, and metabolism. When the ovaries are stimulated to produce excessive amounts of androgen, an accumulation of numerous follicles or cysts can be observed in the ovary. Insulin resistance is also a major cause of hyperandrogenism in PCOS, through stimulating the secretion of ovarian androgen and inhibiting hepatic sex hormone-binding globulin (SHBG) production. ${ }^{17}$ Approximately $80 \%$ to $85 \%$ of women with clinical hyperandrogenism have PCOS. ${ }^{8,18}$ Women with PCOS and hyperandrogenism may experience excess hair growth, acne, and/or abnormal folliculogenesis. Three major pathophysiological pathways have been described, but they are not mutually exclusive. They are ovulatory dysfunction, disordered gonadotropin release, and insulin resistance.

\section{Disordered gonadotropin release and excess androgen release}

In PCOS, hypersecretion of luteinising hormone

\section{多囊卵巢綜合症：常見的生殖內分泌 代謝異常疾病}

\author{
丘芷苓、吳逸晞、張麗冰、馬青雲
}

多囊卵巢綜合症是生育年齡婦女中最常見的內分泌紊亂疾病。雖然傳 統上被視為一種生殖障礙, 但人們越發意識到此症可能會增加心臟代 謝異常的風險。多囊卵巢綜合症患者可能會出現不同種類的症狀。雖 然此症會在生育期內影響患者懷乃的機會, 事實上它在往後的日子增 加患者心臟代謝的問題更不容忽視。多囊卵巢綜合症患者患有血糖異 常或II型糖尿病的風險增加約 2 至 5 倍, 因此有必要定期進行口服葡萄 糖耐量測試的檢測。雖然多囊卵巢綜合症的診斷標準仍在發展階段, 亦不斷進行修訂, 但診斷越見集中在雄激素過多的層面。在沒有雄激 素過多或持續無排卵的情況下, 多形性卵巢形態是否重要仍具爭論。 治理多囊卵巢綜合症的婦女應根據個別患者的需要, 也可能會隨着患 者的年齡而改變。鑑於病情的臨床表現, 最近有關此症存在爭辯, 包 括其名稱是否誤導, 以及應否改名為代謝性生殖綜合症。

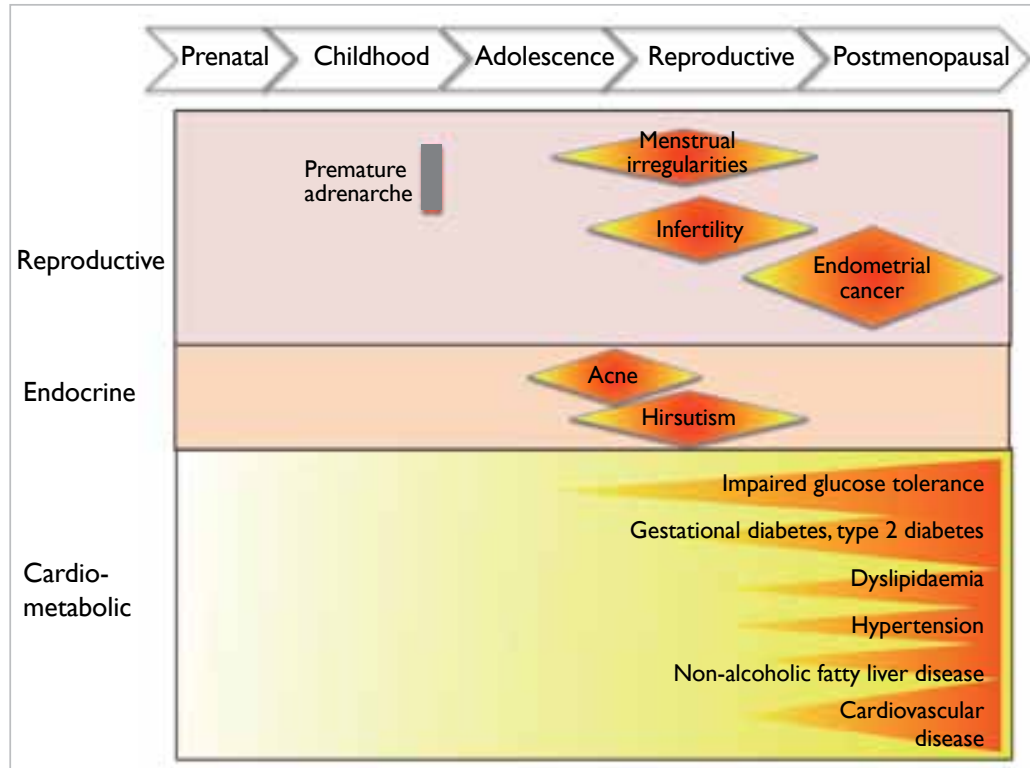

FIG I. Impacts of polycystic ovary syndrome on reproductive, endocrine, and cardiometabolic outcome across the life course

(LH) can lead to an increase in androgen production by the ovarian thecal cells. This is thought to be due to increased gonadotropin-releasing hormone $(\mathrm{GnRH})$ pulse frequency, resulting in increased frequency and pulsatile secretion of $\mathrm{LH}$, and increased levels of $\mathrm{LH}$ relative to follicle-stimulating hormone (FSH) in the circulation. ${ }^{14,19,20}$ There also appears to be resistance to the negative feedback by progesterone to the GnRH pulse generator, which is often present by puberty. The increased LH/FSH ratio, along with some ovarian resistance to $\mathrm{FSH}$, results in excess production of androgens from thecal cells in ovarian follicles, leading to impaired follicular development, and reduced inhibition of the GnRH pulse generator by progesterone, thereby setting up a vicious cycle 
TABLE I. Summary of proposed diagnostic criteria for PCOS in adults ${ }^{6-9} *$

\begin{tabular}{|c|c|c|c|c|}
\hline \multicolumn{2}{|l|}{ Criteria } & \multirow{2}{*}{$\begin{array}{c}\text { National } \\
\text { Institutes of } \\
\text { Health }(1990)^{6}\end{array}$} & \multirow{2}{*}{ 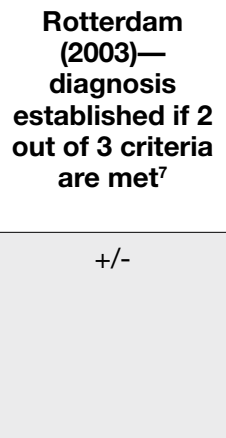 } & \multirow{2}{*}{$\begin{array}{c}\text { Androgen Excess } \\
\text { and PCOS } \\
\text { Society (2009)- } \\
\text { diagnosis requires } \\
\text { hyperandrogenism } \\
\text { with } 1 \text { of } 2 \\
\text { remaining criteria } \\
+\end{array}$} \\
\hline Hyperandrogenism & $\begin{array}{l}\text { Clinical hyperandrogenism } \\
\text { - Acne or hirsutism or androgenic alopecia } \\
\text { and/or } \\
\text { Biochemical hyperandrogenism } \\
\text { - Elevated serum androgen level (total testosterone or } \\
\text { bioavailable testosterone or free testosterone) } \dagger\end{array}$ & & & \\
\hline Oligo-anovulation & $\begin{array}{l}\text { - } \leq 8 \text { Menstrual cycles per year, or frequent bleeding at intervals } \\
<21 \text { days, or infrequent bleeding at intervals }>35 \text { days } \\
\text { - Mid-luteal progesterone documenting anovulation }\end{array}$ & + & $+/-$ & $+/-$ \\
\hline Polycystic ovary & $\begin{array}{l}\text { - }>12 \text { Follicles of } 2-9 \mathrm{~mm} \text { in diameter in at least one ovary } \\
\text { (without a cyst or dominant follicle), and/or } \\
\text { - Ovarian volume }>10 \mathrm{~mL}\end{array}$ & Not required & $+/-$ & $+/-$ \\
\hline
\end{tabular}

Abbreviation: PCOS = polycystic ovary syndrome

* Legend: + indicates an essential criterion for diagnosis; +/- indicates clinical features that are one of the criteria which may need to be present for the diagnosis to be established

+ Given the variability in testosterone level and the suboptimal standardisation of assays, it is difficult to define an absolute level that is diagnostic of PCOS or other causes of hyperandrogenism, and the Task Force recommends familiarity with cut-offs of local assays ${ }^{9}$

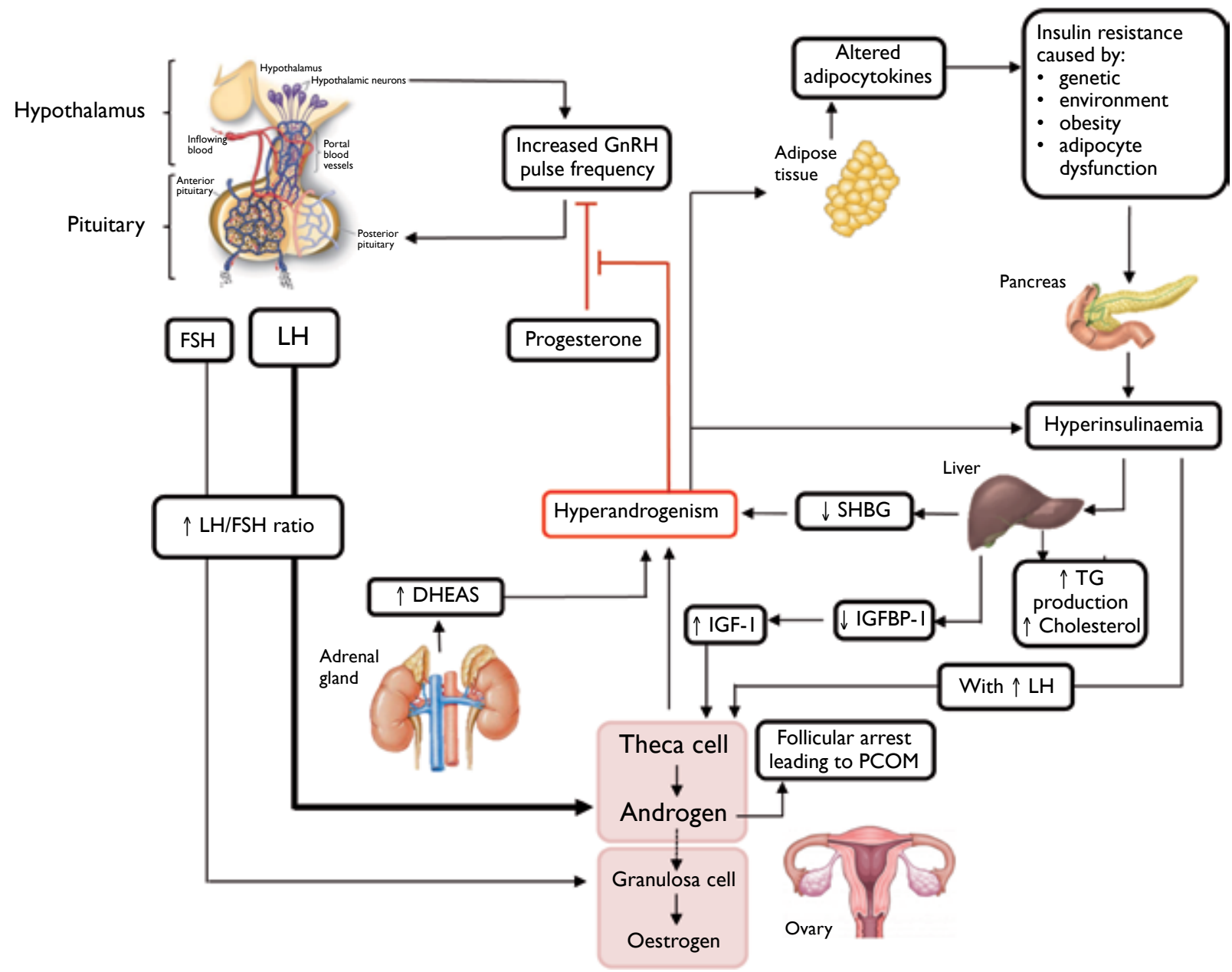

FIG 2. Pathophysiology of polycystic ovary syndrome

Abbreviations: DHEAS = dehydroepiandrosterone sulfate; FSH = follicle-stimulating hormone; GnRH = gonadotropin-releasing hormone; IGF- I = insulin-like growth factor I; IGFBP-I = insulin-like growth factor-binding protein-I; LH = luteinising hormone; PCOM = polycystic ovarian morphology; SHBG = sex hormone-binding globulin; TG = triglycerides 
that exacerbates the hypersecretion of $\mathrm{LH}$, and ovulatory dysfunction. ${ }^{14,19,20}$

\section{Ovulatory dysfunction}

Unlike the ovarian follicular development in healthy women, in PCOS cases, follicle growth is disrupted due to ovarian hyperandrogenism, hyperinsulinaemia from insulin resistance, and intra-ovarian paracrine signalling. Hyperinsulinaemia further impairs follicle growth by amplifying LH-stimulated and insulinlike growth factor 1 (IGF-1)-stimulated androgen production. $^{21-24}$ Hyperinsulinaemia also elevates serum free testosterone levels through decreased hepatic SHBG production, and enhances serum IGF-1 bioactivity through suppression of IGF-binding protein production. ${ }^{25}$ Insulin excess also promotes premature follicle luteinisation through enhanced FSH-induced granulosa cell differentiation, which arrests granulosa cell proliferation and subsequent follicle growth. ${ }^{26}$ Finally, overproduction of antiMüllerian hormone (AMH $)^{27-29}$ by the granulosa cells of ovarian follicles in PCOS appears to antagonise FSH action in small PCOS follicles. ${ }^{30}$ The relatively lower FSH levels contribute to arrested follicular development in the ovary, leading to amenorrhoea, anovulation, and polycystic morphology. ${ }^{8,16}$

\section{Insulin resistance}

In PCOS cases, there is an increased level of bioavailable androgens that leads to increased insulin resistance in peripheral tissues (mostly in the skeletal muscle). ${ }^{31}$ Insulin resistance causes compensatory hyperinsulinaemia and might contribute to hyperandrogenism and gonadotropin aberrations through several mechanisms. Insulin may act directly in the hypothalamus, the pituitary or both and thereby contribute to abnormal gonadotropin levels. By facilitating the stimulatory role of LH, hyperinsulinaemia leads to further increase in ovarian androgen production in theca calls. ${ }^{32}$ High insulin can also serve as a co-factor to stimulate adrenocorticotropic hormone-mediated androgen production in the adrenal glands. ${ }^{33}$ Moreover, an insulin-induced decrease in the production of SHBG in the liver increases the amount of free bioavailable androgens. ${ }^{34}$

Most women with PCOS, particularly those who are overweight or obese, do in fact have insulin resistance and compensatory hyperinsulinaemia, ${ }^{35,36}$ partly attributable to an intrinsic insulin resistance mechanism. ${ }^{36-38}$

Using the homeostasis model assessment, 50\% to $70 \%$ of women with PCOS demonstrate insulin resistance. Using the gold standard technique of euglycaemic hyperinsulinaemic clamp, it was found that PCOS exhibits insulin resistance that is independent of obesity, and is present even among lean patients with PCOS, but this is further exacerbated in the presence of obesity. ${ }^{39,40}$

A stepwise increase in the prevalence of glucose intolerance with increasing body mass index (BMI) has been described in cross-sectional studies performed in women with this disorder. ${ }^{41}$ Although most women with PCOS have normal insulin secretory responsiveness, studies have suggested that PCOS women, particularly those with a family history of type 2 diabetes (T2D), have impaired $\beta$-cell function or a subnormal disposition index (an index of $\beta$-cell function that takes insulin resistance into account). ${ }^{16,42,43}$

\section{Adipose dysfunction}

Although the full molecular mechanisms underlying insulin resistance in PCOS remain unclear, primary defects in insulin-medicated glucose transport, ${ }^{44}$ GLUT4 production, ${ }^{45}$ and insulin or adrenergic regulated lipolysis ${ }^{46}$ in adipocytes (and sometimes in myocytes and fibroblasts) have been reported. Insulin resistance in PCOS contributes to the dysfunctional adipogenesis to some degree from an impaired capacity of regional adipose tissue storage to properly expand with increased dietary caloric intake. ${ }^{47-49}$ Adipose tissue secretes numerous factors to regulate metabolic function, appetite, neural activity, and digestion. This tissue is also heavily infiltrated by macrophages, and a crosstalk exists between adipocytes, macrophages, and pluripotent cells for complex paracrine interactions. It is known that dysregulation of adipokine production, such as adiponectin, by macrophage-secreted cytokines in PCOS facilitates the development of insulin resistance. ${ }^{50}$ Other adipokines including leptin, retinol-binding protein 4 , and visfatin have also been implicated. ${ }^{51}$ Improved understanding of the underlying mechanisms that govern adipose tissue dysfunction and insulin resistance in PCOS would be beneficial in the identification of novel therapeutic targets for PCOS and other related disorders. ${ }^{16}$

\section{Intrauterine environment}

In humans, rhesus monkeys and sheep, inappropriate testosterone exposure during fetal life alters the developmental trajectory of the female leading to PCOS-like phenotypes, such as phenotypic masculinisation; reproductive, neuroendocrine, ovarian disruptions; and hyperinsulinaemia. ${ }^{52}$ In a human study, it has been shown that there is an increased prevalence of PCOS in women with classic $\mathrm{CAH}$ and congenital adrenal virilising tumours. ${ }^{53}$ In one human study, higher testosterone levels compared with those usually observed in normal females were found in the umbilical vein of female infants born to mothers with $\mathrm{PCOS}^{54}$; yet, another prospective study that investigated the relationship between prenatal androgen exposure and the 
development of PCOS in female adolescence did not confirm any association between these variables. ${ }^{55}$

Excess fetal exposure to maternal androgens is thought to contribute to induction of the PCOS phenotype in offspring/children. Nonetheless, more clinical studies are needed to confirm the role of intrauterine androgen exposure on human fetal development.

\section{Recent insights from genetic studies}

Polycystic ovary syndrome has a high heritability of approximately $80 \%$. Although a large number of candidate gene studies have been conducted, no genetic variants have been found to be consistently associated with PCOS. Recent hypothesis-free genome-wide association studies using high-density genotyping arrays that systematically investigate common variants across the genome have identified several genetic loci to be significantly associated with PCOS (Table 2). ${ }^{56}$ These have shed light on the important role of the gonadotropin axis in the pathogenesis of PCOS, as well as several other novel pathways, including epidermal growth factor signalling. Interestingly, genetic studies have revealed a significant overlap of findings when different diagnostic criteria of PCOS have been applied, highlighting greater homogeneity than previously appreciated. ${ }^{16,56,57}$

\section{Clinical features and co-morbidities}

\section{Gynaecological and reproductive dysfunction}

Menstrual dysfunction is common and is characterised by oligomenorrhoea and, less often, amenorrhoea. Nonetheless, menstrual problems are frequently neglected and anovulatory infertility is frequently the initial complaint for which the patient seeks medical advice. Women with PCOS have an increased risk of miscarriage, gestational diabetes, pre-eclampsia, and preterm labour. ${ }^{58-60}$ A metaanalysis highlighted that the risks of gestational diabetes, pregnancy-induced hypertension, and preeclampsia are approximately 3 -fold, whereas the risk for preterm labour is approximately 2-fold among women with PCOS. ${ }^{58}$ The reasons for the adverse pregnancy outcomes are unclear, but hypersecretion of LH, hyperandrogenaemia and hyperinsulinaemia have all been postulated. Due to anovulatory dysfunction and consequent long-term unopposed oestrogen stimulation, PCOS patients are at increased risk of endometrial cancer. ${ }^{61,62}$ Nonetheless, there is currently no consensus to support routine biopsy or ultrasound of the endometrium for endometrial hyperplasia or cancer screening in asymptomatic women due its poor diagnostic accuracy. ${ }^{63}$

TABLE 2. Genetic loci associated with polycystic ovary syndrome discovered in genome-wide association studies ${ }^{56}$

\begin{tabular}{|c|c|c|c|c|c|c|}
\hline Chromosome & Nearest gene & GWAS top SNP & Odds ratio & $P$ value & Discovery population & Replicated population(s) \\
\hline $2 p 16.3$ & LHCGR & rs13405728 & 1.41 & $7.55 \times 10^{-21}$ & Chinese & Europeans, Indians \\
\hline $2 \mathrm{p} 16.3$ & FSHR & rs2268361 & 1.15 & $9.89 \times 10^{-13}$ & Chinese & Europeans, Arabs, Chinese \\
\hline $2 p 21$ & THADA & rs13429458 & 1.49 & $1.73 \times 10^{-23}$ & Chinese & Europeans, Chinese \\
\hline 2q34 & ERBB4 & rs1351592 & 1.18 & $1.2 \times 10^{-12}$ & Chinese & - \\
\hline $5 q 31.1$ & $R A D 50$ & rs13164856 & 1.13 & $3.5 \times 10^{-9}$ & Chinese & - \\
\hline $8 p 32.1$ & GATA4 & rs804279 & 1.35 & $8.0 \times 10^{-10}$ & Chinese & - \\
\hline 9q33.3 & DENND1A & rs2479106 & 1.34 & $8.12 \times 10^{-19}$ & Chinese & Europeans \\
\hline \multirow[t]{2}{*}{$9 q 22.32$} & C9orf3 & rs4385527 & 1.19 & $5.87 \times 10^{-9}$ & Chinese & Chinese, Europeans \\
\hline & & rs3802457 & 1.30 & $5.28 \times 10^{-14}$ & Chinese & - \\
\hline $11 \mathrm{p} 14.1$ & $F S H B$ & rs11031006 & 1.16 & $1.9 \times 10^{-8}$ & European & Europeans, Chinese \\
\hline \multirow[t]{2}{*}{$11 q 22.1$} & YAP1 & rs1894116 & 1.27 & $1.08 \times 10^{-22}$ & Chinese & Europeans, Chinese \\
\hline & & rs11225154 & 1.22 & $7.6 \times 10^{-11}$ & European & Chinese \\
\hline $12 q 14.3$ & HMGA2 & rs2272046 & 1.43 & $1.95 \times 10^{-21}$ & Chinese & Europeans \\
\hline $12 q 13.2$ & $R A B 5 B / S U O X$ & rs705702 & 1.27 & $8.64 \times 10^{-26}$ & Chinese & Europeans \\
\hline $12 q 21.2$ & KRR1 & rs1275468 & 1.13 & $1.9 \times 10^{-8}$ & Europeans & - \\
\hline $16 q 12.1$ & TOX3 & rS4784165 & 1.15 & $3.64 \times 10^{-11}$ & Chinese & Europeans \\
\hline $19 p 13.3$ & INSR & rs2059807 & 1.14 & $1.09 \times 10^{-8}$ & Chinese & Europeans \\
\hline $20 \mathrm{q} 13.2$ & SUM01P1 & rs6022786 & 1.13 & $1.83 \times 10^{-9}$ & Chinese & - \\
\hline
\end{tabular}

Abbreviations: GWAS = genome-wide association study; SNP = single-nucleotide polymorphism 


\section{Endocrine dysfunction}

Women with PCOS have varying degrees and manifestations of androgen excess. Clinical signs of hyperandrogenism include acne, hirsutism, malepattern hair loss, and/or elevated serum androgen concentrations. Hirsutism is the most common symptom of hyperandrogenism, affecting up to $70 \%$ of women with PCOS. It is commonly noted on the upper lip, chin, periareolar area, in the mid-sternum, and along the linea alba of the lower abdomen. There is substantial ethnic variation in hirsutism where Asian women with PCOS have a lesser degree of hirsutism. ${ }^{8}$ Signs of more severe androgen excesssuch as deepening of the voice, breast atrophy, and clitoromegaly-occur rarely and suggest the possibility of ovarian hyperthecosis or an androgensecreting tumour.

\section{Metabolic dysfunction and cardiovascular risks}

Polycystic ovary syndrome is associated with cardiovascular risk factors, including obesity, hypertension, glucose intolerance, dyslipidaemia, and obstructive sleep apnoea. ${ }^{64}$ The high prevalence of metabolic disturbances and the consequent increase in the long-term risk of T2D indicate that PCOS should be considered a general health problem rather than just a reproductive syndrome. Most investigators found that at least one half of PCOS women are obese. ${ }^{8}$ The prevalence of obesity in PCOS varies widely with the population studied, similar to the wide variability in prevalence of obesity in the general population.

Insulin resistance occurs in $60 \%$ to $80 \%$ of women with PCOS, and $95 \%$ of obese women with PCOS. The risk of T2D is increased in PCOS, particularly in women with a first-degree relative with T2D. ${ }^{65}$ In a systematic review, it was estimated that the prevalence of impaired glucose tolerance and T2D was as high as $31 \%$ to $35 \%$, and $7.5 \%$ to $20 \%$, respectively, in women with PCOS by their fourth decade, and the risks were significantly higher at all ages and all weights even in young or lean subjects with PCOS. ${ }^{66,67}$ In Hong Kong, the prevalence of T2D under 35 years old is $0.6 \%$ in the general population, but $7.5 \%$ in women with PCOS. ${ }^{68}$

Dyslipidaemia is the most common metabolic abnormality in PCOS. Most studies of women with PCOS have demonstrated low high-density lipoprotein cholesterol and high triglyceride concentrations, consistent with their insulin resistance, as well as an increase in low-density lipoprotein cholesterol. ${ }^{69-71}$

Metabolic syndrome, characterised by a cluster of cardiometabolic risk factors associated with insulin resistance, is a disease with a large health impact as it confers a 5 -fold increase in risk of T2D and a 2-fold increase in risk of cardiovascular diseases..$^{72} \mathrm{~A}$ cross-sectional study evaluated the cardiometabolic risk factors in 295 Hong Kong Chinese women with PCOS with a mean age of 30 years. ${ }^{68}$ It found that the prevalence of metabolic syndrome in this cohort was $24.9 \%$ despite their relatively young age, a 5 -fold increase in risk compared with women without PCOS even after controlling for age and BMI. ${ }^{68} \mathrm{In}$ another study involving 170 Asian women with PCOS, metabolic syndrome as defined according to the International Diabetes Federation criteria was present in $35.3 \%$ of the subjects. ${ }^{73}$

The prevalence of non-alcoholic fatty liver disease (including non-alcoholic steatohepatitis), and obstructive sleep apnoea is also increased in women with PCOS. Even after controlling for BMI, women with PCOS are still 30 times more likely to have sleep-disordered breathing and 9 times more likely than controls to have daytime sleepiness. ${ }^{74,75}$

The presence of obesity, insulin resistance, impaired glucose tolerance (or T2D), and dyslipidaemia may predispose women with PCOS to coronary heart disease. An excess risk of coronary heart disease or stroke in women with PCOS, however, is not well established due to the lack of long-term prospective studies. Available studies are mostly too small to detect differences in event rates, and none have shown an evident increase in cardiovascular events. ${ }^{76-79}$ Therefore, the focus has been on risk factors of cardiovascular disease although these may not necessarily equate with events or mortality. Studies have found that women with PCOS have an increased carotid intima media thickness and coronary artery calcification, the two major surrogate markers for atherosclerotic cardiovascular disease. ${ }^{80-82}$ Serum concentrations of C-reactive protein, a biochemical predictor of cardiovascular disease, also appear to be commonly elevated in women with PCOS. ${ }^{83}$

\section{Patient evaluation}

\section{Clinical features}

The history-taking should include detailed inquiry about growth and sexual development, menstrual pattern, reproductive history, medical and drug history, symptoms of androgen excess, co-existing cardiovascular risk factors such as tobacco and alcohol use, and family history. Drug history is important as a history or current use of sodium valproate has been shown to be associated with PCOS.

During the physical examination, it is essential to search for signs of androgen excess (hirsutism, acne, androgenic alopecia) and insulin resistance (acanthosis nigricans). Modified Ferriman-Gallwey scoring is the method generally used to evaluate clinical hirsutism, but is affected by subjective 
variability and cosmetic treatments. It has been suggested that in East Asian patients, a lower cut-off of the modified Ferriman-Gallwey score (of 3) should be used instead of the usual cut-off of $8 . .^{16,19}$ As cosmetic hair removal is common in many Asian countries, evaluation of hirsutism should always include enquiry about any previous hair-removal procedures. Assessment of blood pressure, BMI, and waist circumference is also essential. Features of virilisation, Cushing's syndrome, and thyroid dysfunction should also be looked for and excluded. ${ }^{19}$

\section{Biochemical features}

Laboratory measurements should include tests to achieve the diagnosis, exclude other endocrine problems, and evaluate cardiovascular risk factors. In someone with clinical signs of hyperandrogenism, one could argue that biochemical testing is not necessary according to current diagnostic criteria. Most expert groups, however, suggest measuring total testosterone concentration in women who present with hirsutism. Women with PCOS mostly have high-normal or borderline elevated levels of testosterone.

Elevated total testosterone is the most direct evidence for androgen excess, but it is important to note that most assays are relatively inaccurate at the lower levels present in females, and use of mass spectrometry-based assays of total testosterone are more accurate and preferred. ${ }^{9}$ Measurement of free testosterone is a more sensitive test, but commercially available free testosterone assays are often unreliable. The free testosterone index, calculated by total testosterone divided by SHBG, is considered more reliable but is not routinely performed due to the high cost of measuring SHBG. ${ }^{9}$ Serum LH and FSH levels should be measured at the early follicular phase of the menstrual cycle. Ovulatory assessment such as mid-luteal progesterone measurement is sometimes required in patients seeking infertility treatment. In rare instances where there are rapidly progressive features of hyperandrogenism, virilising symptoms, or markedly elevated androgen levels (such as a serum testosterone $>5 \mathrm{nmol} / \mathrm{L}$ ), additional investigations to exclude an androgen-secreting tumour maybe indicated, including checking cortisol, dehydroepiandrosterone sulfate, and imaging of the adrenal glands and ovaries. As mentioned earlier, $\mathrm{AMH}$ is implicated in the pathogenesis of PCOS, and recent studies have highlighted its potential utility in the diagnosis of women with PCOS,$^{16}$ although no diagnostic cut-off value has been defined yet due to the heterogeneity between the different AMH assay methods.

Blood tests to exclude other endocrine problems include thyroid function tests, prolactin, or tests to exclude other underlying causes of excess androgens, including 17-hydroxyprogesterone to exclude late-onset $\mathrm{CAH}$ and the 1-mg overnight dexamethasone suppression test to exclude Cushing's syndrome. It is sometimes noted that women with PCOS have mildly elevated prolactin. ${ }^{20}$ If the level of 17-hydroxyprogesterone is borderline elevated, a short synacthen test with measurement of 17-hydroxyprogesterone may be indicated to exclude late-onset $\mathrm{CAH} .{ }^{19}$

Assessment of cardiovascular risk factors includes an oral glucose tolerance test (OGTT) and fasting lipid profiles. Fasting glucose, although more convenient, has been shown to underestimate diabetes prevalence and cardiovascular risk when compared with OGTT, particularly in obese subjects. Measuring fasting glucose alone is therefore inadequate for the assessment of dysglycaemia in women with PCOS. ${ }^{84}$ Patients with normal glucose tolerance should be re-screened at least once every 2 years, or more frequently if additional risk factors are identified. Patients with impaired glucose tolerance should be screened annually for development of T2D.

\section{Ultrasound features}

The use of ultrasound in the diagnosis of PCOS must be tempered by an awareness of the broad spectrum of women with ultrasonographic findings characteristic of polycystic ovaries. ${ }^{85}$ If the patient has both oligo-ovulation and hyperandrogenism, a transvaginal ultrasound to document polycystic ovaries is not necessary according to the Rotterdam criteria. In women who are ready to conceive, ultrasound can be used to monitor and document ovulation.

The ultrasound criteria in the diagnosis of PCOS have evolved since the first ultrasound description of polycystic ovaries in $1986 .{ }^{8}$ The Rotterdam criteria described polycystic ovaries as the presence of $\geq 12$ follicles in each ovary measuring 2 to $9 \mathrm{~mm}$ in diameter and/or increased ovarian volume of $>10 \mathrm{~mL}$. One ovary fulfilling this definition is sufficient to define polycystic ovaries. More recently, it has been proposed that if newer technology such as ultrasound machines with transducer frequency of $\geq 8 \mathrm{MHz}$ are available, then raising the follicle number per ovary to 25 for diagnosing PCOS would be more specific. ${ }^{86}$

Ultrasonography is operator-dependent and requires expertise. Transvaginal ultrasound is the method of choice, but is practically difficult in patients without previous sexual experience. Transrectal ultrasound examination is an alternative in women where transvaginal scan is not possible. Transabdominal ultrasound has poorer resolution, especially in obese subjects. Recent research suggests that ultrasound might be useful to supplement the diagnosis in the event of ovulatory disturbance without hyperandrogenism. ${ }^{12,86,87}$ 


\section{Treatment approach}

The management of women with polycystic ovary varies according to the main symptoms and primary problem experienced by the patient. The particular needs of the patient may change according to different stages of the life course, from adolescence through to reproductive age. ${ }^{88}$ Hence management should involve a multidisciplinary approach involving paediatricians, gynaecologists, endocrinologists, family physicians, dietitians, clinical psychologists, and surgeons, as appropriate. ${ }^{84}$

\section{Management of menstrual irregularity}

Menstrual irregularity is one of the most common presenting symptoms of patients with PCOS, and often reflects underlying ovarian dysfunction and anovulation. Chronic anovulation and secondary amenorrhoea can be associated with endometrial hyperplasia and increased risk of endometrial carcinoma, along with other complications associated with amenorrhoea including osteoporosis. Overweight women with PCOS should be encouraged to lose weight; as low as a $5 \%$ reduction in body weight is associated with improvement in amenorrhoea. ${ }^{88-90}$ Previous studies have highlighted that a lifestyle modification programme is associated with improvement in menses, hirsutism, biochemical hyperandrogenism, and insulin resistance. ${ }^{90,91}$

Progestagens can be administered both as a diagnostic test to induce progesterone withdrawal, as well as to treat amenorrhoea. Cyclical progestagens, preferably given 12 to 14 days per month, can be used to ensure regular withdrawal bleeding to avoid endometrial hyperplasia, and are associated with less-adverse cardiometabolic effects than combined oestradiol-progestagen pills. Periodic short courses of progestogen (2-3 monthly) are an alternative option.

The use of the combined oral contraceptive (COC) pill, with its beneficial effects on suppressing excess androgen and its manifestations, has been a commonly used and convenient treatment for amenorrhoea, with the added benefit of providing contraception. In women with PCOS, COC formulations containing less androgenic progestagens are preferred. Nonetheless, there has been some debate about whether the use of COC may cause exacerbation of cardiometabolic risk..$^{92}$ Contra-indications to use of a COC include heavy smokers aged $\geq 35$ years, those with hypertension or established cardiac disease, and those with multiple cardiovascular risk factors. ${ }^{93}$ Nevertheless, current recommendations suggest that this is a useful alternative, although clinicians should monitor for changes in body weight, blood pressure, lipid profile as well as dysglycaemia if patients are prescribed $\mathrm{COC}$, especially if the patient is overweight.

\section{Management of hyperandrogenism}

As highlighted earlier, administration of an oestrogencontaining oral contraceptive has beneficial effects on hyperandrogenism. Furthermore, the oral contraceptive pill containing the anti-androgenic progestagen cyproterone acetate, administered in cyclical doses, or drospirenone-containing COC might be beneficial for hirsutism. ${ }^{16}$ The use of cyproterone-containing pills to alleviate hyperandrogenic symptoms should ideally be limited to short-term use and discontinued 3 to 4 months after symptom resolution due to higher thromboembolic risk than the first-line COC pills. ${ }^{94}$ Other anti-androgens, such as finasteride, are sometimes used in severe cases of hirsutism, although again patients need to ensure they avoid conceiving whilst on anti-androgenic drugs.

In most circumstances, women may elect to use cosmetic measures to treat the clinical manifestations of hyperandrogenism. Different cosmetic approaches for hair removal-including shaving, waxing, and electrolysis-have variable efficacy and duration of effects. Laser therapy in the form of photoepilation represents a more permanent solution but is also more costly. ${ }^{4}$ Other options for treatment of hirsutism due to hyperandrogenism include use of topical eflornithine that may help reduce excess facial hair.

\section{Management of anovulatory infertility}

The presence of anovulatory infertility can be investigated by measurement of progesterone in the mid-luteal phase of the menstrual cycle (eg day 21 of a 28 -day cycle, or day 28 of a 35-day cycle), and can help to establish the presence of anovulation. The monitoring of basal body temperature to confirm ovulation does not predict ovulation reliably, and is no longer recommended..$^{95} \mathrm{In}$ patients with anovulatory infertility, clomiphene treatment is usually considered the first-line treatment. Clomiphene should be started at a low dose (eg 50 mg daily for 5 days per cycle) and gradually increased until the lowest effective dose that achieves ovulation is reached, but this requires close monitoring, especially for the potential side-effects of multiple pregnancy and ovarian hyperstimulation. Treatment can be repeated if unsuccessful, but the majority of patients who respond usually do so within the first three cycles. ${ }^{4,96}$ The highest recommended dose for clomiphene is $150 \mathrm{mg}$, and if the woman still does not respond, second-line treatment should be considered.

Metformin has beneficial effects on anovulation. In a systematic review and meta-analysis, metformin was found to be associated with increased success at inducing ovulation. ${ }^{97}$ Doses vary in clinical trials from $1 \mathrm{~g}$ daily to higher doses. In a multicentre 
randomised controlled trial, therapy-naïve PCOS women who received metformin had a significantly lower live birth rate than women who conceived through clomiphene alone, or were treated with a combination of clomiphene and metformin. ${ }^{98}$ The use of metformin as a co-treatment with clomiphene has been shown to improve ovulation in women with clomiphene-resistant PCOS. ${ }^{99}$ Metformin is in general stopped after successful conception, although some advocate continued use during the first trimester to reduce the risk of spontaneous miscarriage. This is still an area of controversy, and the pros and cons of continuing metformin should be carefully discussed. Metformin is known to cross the placenta but it has also been shown to be a useful treatment for gestational diabetes.

Aromatase inhibitors reduce circulating oestrogen levels, lead to a rise in pituitary FSH, and have previously shown beneficial effects in a metaanalysis. Letrozole, an aromatase inhibitor, was found to be superior to clomiphene in achieving live births in a randomised clinical trial. ${ }^{100}$

Daily injections of exogenous gonadotropins, including recombinant $\mathrm{FSH}$ or menopausal gonadotropin, have been found to improve ovulation induction among women who did not respond to other treatments. This treatment requires careful monitoring, and should be used with a 'chronic lowdose step-up' approach as outlined by the ESHRE/ ASRM to avoid multiple pregnancies or ovarian hyperstimulation syndrome..$^{96,101}$

\section{Ovarian surgery/drilling/laparoscopic ovarian diathermy}

Surgical procedures such as ovarian wedge resection or ovarian drilling by diathermy or laser lead to a decreased number of antral follicles, reduced ovarian androgen production, and improved ovulation. ${ }^{16}$ Ovarian wedge resection is no longer performed due to the higher extent of adhesion formation and ovarian tissue damage. Ovarian drilling has been used as an alternative to exogenous gonadotropins for treatment of anovulatory infertility, with similar success rates. The main limitations include the potential for formation of adhesions, and reduced ovarian reserve. In a retrospective analysis of Chinese women with PCOS treated by laser diathermy, spontaneous ovulation rates and cumulative pregnancy rates were similar regardless of the presence or absence of metabolic syndrome. ${ }^{102}$

\section{Assisted reproductive procedures}

In women who fail second-line treatment such as metformin, ovarian drilling or ovarian stimulation with gonadotropins, third-line treatment such as intrauterine insemination or in-vitro fertilisation can be considered. ${ }^{17}$

\section{Management of cardiometabolic risk}

Women with PCOS are at substantially increased cardiometabolic risk, and therefore should undergo periodic evaluation of associated risk factors. ${ }^{4}$ Overweight women with PCOS should undergo comprehensive evaluation by a dietitian, and be encouraged to lose weight. Weight loss of approximately $5 \%$ is already associated with improved metabolic parameters as well as reproductive outcome. Even among women with normal BMI, those with PCOS appear to have increased visceral adiposity that contributes to the endogenous insulin resistance, and is correlated with metabolic parameters, fatty liver as well as carotid intimal-medial thickness. ${ }^{103}$

In addition to lifestyle measures, women should be screened for glucose intolerance by an OGTT. Screening using fasting glucose alone is inadequate in this high-risk population. ${ }^{4}$ Presence of impaired glucose tolerance may warrant treatment with metformin given the multiple metabolic and reproductive benefits, regardless of whether there is clinical evidence of insulin resistance. Overt diabetes should be treated using an appropriate combination of dietary treatment, metformin, other oral glucose-lowering agents, and in some cases, insulin. The choice of agent should depend on the underlying pathophysiology (eg whether obesity is present), but also take into account the fertility wishes and plans of the patient. Metformin in combination with lifestyle intervention has been found to be associated with greater reduction in BMI compared with lifestyle intervention alone. ${ }^{104}$ Several studies have demonstrated the efficacy of thiazolidinediones in improving metabolic parameters as well as menses and hyperandrogenism in women with PCOS. Due to possible adverse effects, however, this class of agent is currently not recommended for treatment of insulin resistance among women with PCOS.4

Treatment of hypertension likewise should take into account the fertility wishes of the patient. Screening for other secondary causes of youngonset hypertension may be necessary, especially if atypical features such as proteinuria are present. Preferred anti-hypertensive agents in women contemplating pregnancy would be the older agents such as methyldopa. It is notable that women with pre-existing hypertension are more likely to develop hypertension-related complications during pregnancy, and therefore require more strict surveillance during pregnancy. Hyperlipidaemia can be managed using dietary measures, and in some cases, lipid-lowering agents such as HMG CoA (3-hydroxy-3-methylglutaryl coenzyme A) reductase inhibitors. If there are plans for pregnancy, drug treatment with lipid-lowering treatment should be withheld. 
Psychological distress, anxiety, and depression are common among women with PCOS, and may be linked to some of the skin complications such as hirsutism and acne or presence of menstrual and fertility problems; all these impact on psychological well-being. Clinicians need to have a high level of awareness and screen for these symptoms when appropriate and offer the necessary referrals for psychological support. Sleep-disordered breathing including obstructive sleep apnoea is also common, impacts sleep quality, and can exacerbate both mood problems as well as cardiometabolic risk. It should be screened for and managed accordingly. In those with marked obesity, bariatric surgery is an option to address obesity and associated metabolic abnormalities. Interestingly, a systematic review including 13 primary studies found that the incidence of PCOS was reduced from $45.6 \%$ to $7.1 \%$ after bariatric surgery. ${ }^{105}$

The screening and management of metabolic abnormalities is particularly relevant in those women with PCOS who are planning a pregnancy or undergoing fertility treatment. Women with PCOS are at increased risk of different complications including gestational diabetes and pre-eclampsia. Undiagnosed gestational diabetes/maternal hyperglycaemia or poorly controlled blood pressure all contribute to poorer pregnancy outcome among women with PCOS. Optimal management before pregnancy and intrapartum can help to minimise the risk of these pregnancy complications.

\section{Conclusions}

Polycystic ovary syndrome is a multi-faceted syndrome that is becoming increasingly recognised, and is an important contributor to multiple medical and reproductive problems. As illustrated in this review, given the multiple reproductive and metabolic complications associated with PCOS, patients may seek medical attention via a variety of different channels, and may present to clinicians through different disciplines. Clinicians therefore need to recognise the multi-faceted nature of this complex disorder and be aware of the associated complications. Diagnostic criteria are still evolving, although currently the Rotterdam criteria remain the most widely accepted. Given the burden of metabolic complications associated with the disorder, there has been much recent discussion regarding the potential need to rename the syndrome to better highlight its metabolic consequences, in addition to the known reproductive features. The long-term risks of the different complications are still not clearly defined, given the scarcity of well-conducted prospective studies. These limitations in our current knowledge highlight the need to follow-up this group of highrisk women.

\section{Acknowledgement}

RCW Ma acknowledges support from the Research Grants Council General Research Fund (Ref. 14110415).

\section{Declaration}

All authors have disclosed no conflicts of interest.

\section{References}

1. Stein IF, Leventhal ML. Amenorrhea associated with bilateral polycystic ovaries. Am J Obstet Gynecol 1935;29:181-91.

2. March WA, Moore VM, Willson KJ, Phillips DI, Norman RJ, Davies MJ. The prevalence of polycystic ovary syndrome in a community sample assessed under contrasting diagnostic criteria. Hum Reprod 2010;25:544-51.

3. Chen X, Yang D, Mo Y, Li L, Chen Y, Huang Y. Prevalence of polycystic ovary syndrome in unselected women from southern China. Eur J Obstet Gynecol Reprod Biol 2008;139:59-64.

4. Legro RS, Arslanian SA, Ehrmann DA, et al. Diagnosis and treatment of polycystic ovary syndrome: an Endocrine Society clinical practice guideline. J Clin Endocrinol Metab 2013;98:4565-92.

5. Gibson-Helm M, Teede H, Dunaif A, Dokras A. Delayed diagnosis and a lack of information associated with dissatisfaction in women with polycystic ovary syndrome. J Clin Endocrinol Metab 2017;102:604-12.

6. Zawadski J, Dunaif A. Diagnostic criteria for polycystic ovary syndrome: towards a rational approach. In: Dunaif A, Givens JR, Haseltine FP, Merriam GR, editors. Polycystic ovary syndrome. Boston: Blackwell Scientific Publications; 1992: 377-84.

7. Rotterdam ESHRE/ASRM-Sponsored PCOS Consensus Workshop Group. Revised 2003 consensus on diagnostic criteria and long-term health risks related to polycystic ovary syndrome. Fertil Steril 2004;81:19-25.

8. Azziz R, Carmina E, Dewailly D, et al. The Androgen Excess and PCOS Society criteria for the polycystic ovary syndrome: the complete task force report. Fertil Steril 2009;91:456-88.

9. Rosner W, Auchus RJ, Azziz R, Sluss PM, Raff H. Position statement: utility, limitations, and pitfalls in measuring testosterone: an Endocrine Society position statement. J Clin Endocrinol Metab 2007;92:405-13.

10. Evidence-based Methodology Workshop on Polycystic Ovary Syndrome (PCOS). December 3-5, 2012. Available from: https://www.nichd.nih.gov/about/meetings/2012/ Pages/120512.aspx. Accessed 10 Jul 2017.

11. Lam PM, Ma RC, Cheung LP, Chow CC, Chan JC, Haines CJ. Polycystic ovarian syndrome in Hong Kong Chinese women: patient characteristics and diagnostic criteria. Hong Kong Med J 2005;11:336-41.

12. Boyle JA, Teede HJ. PCOS: Refining diagnostic features in PCOS to optimize health outcomes. Nat Rev Endocrinol 2016;12:630-1.

13. Rojas J, Chávez M, Olivar L, et al. Polycystic ovary syndrome, insulin resistance, and obesity: navigating the pathophysiologic labyrinth. Int J Reprod Med 2014;2014:719050.

14. Cheung LP. Polycystic ovary syndrome: not only a 
gynaecological disease. J Paediatr Obstet Gynaecol 2008(May/Jun):125-31.

15. Diamanti-Kandarakis E, Piperi C. Genetics of polycystic ovary syndrome: searching for the way out of the labyrinth. Hum Reprod Update 2005;11:631-43.

16. Azziz R, Carmina E, Chen Z, et al. Polycystic ovary syndrome. Nat Rev Dis Primers 2016;2:16057.

17. Goodarzi MO, Dumesic DA, Chazenbalk G, Azziz R. Polycystic ovary syndrome: etiology, pathogenesis and diagnosis. Nat Rev Endocrinol 2011;7:219-31.

18. Azziz R, Carmina E, Dewailly D, et al. Positions statement: criteria for defining polycystic ovary syndrome as a predominantly hyperandrogenic syndrome: an Androgen Excess Society guideline. J Clin Endocrinol Metab 2006;91:4237-45.

19. McCartney CR, Marshall JC. Clinical practice. Polycystic ovary syndrome. N Engl J Med 2016;375:54-64.

20. Franks S. Polycystic ovary syndrome. N Engl J Med 1995;333:853-61.

21. Agarwal SK, Judd HL, Magoffin DA. A mechanism for the suppression of estrogen production in polycystic ovary syndrome. J Clin Endocrinol Metab 1996;81:3686-91.

22. Jakimiuk AJ, Weitsman SR, Magoffin DA. 5alpha-reductase activity in women with polycystic ovary syndrome. J Clin Endocrinol Metab 1999;84:2414-8.

23. Moghetti P, Castello R, Negri C, et al. Metformin effects on clinical features, endocrine and metabolic profiles, and insulin sensitivity in polycystic ovary syndrome: a randomized, double-blind, placebo-controlled 6-month trial, followed by open, long-term clinical evaluation. J Clin Endocrinol Metab 2000;85:139-46.

24. Bergh C, Carlsson B, Olsson JH, Selleskog U, Hillensjö T. Regulation of androgen production in cultured human thecal cells by insulin-like growth factor I and insulin. Fertil Steril 1993;59:323-31.

25. Balen AH, Conway G, Homburg R, Legro R. Polycystic ovary syndrome: A guide to clinical management. UK: Taylor \& Francis; 2006.

26. Franks S, Gilling-Smith C, Watson H, Willis D. Insulin action in the normal and polycystic ovary. Endocrinol Metab Clin North Am 1999;28:361-78.

27. Knight PG, Glister C. Local roles of TGF-beta superfamily members in the control of ovarian follicle development. Anim Reprod Sci 2003;78:165-83.

28. Seifer DB, MacLaughlin DT, Cuckle HS. Serum mullerianinhibiting substance in Down's syndrome pregnancies. Hum Reprod 2007;22:1017-20.

29. Visser JA, de Jong FH, Laven JS, Themmen AP. AntiMüllerian hormone: a new marker for ovarian function. Reproduction 2006;131:1-9.

30. Pellatt L, Hanna L, Brincat M, et al. Granulosa cell production of anti-Müllerian hormone is increased in polycystic ovaries. J Clin Endocrinol Metab 2007;92:240-5.

31. Dunaif A. Insulin resistance and the polycystic ovary syndrome: mechanism and implications for pathogenesis Endocr Rev 1997;18:774-800.

32. Diamanti-Kandarakis E, Argyrakopoulou G, Economou F, Kandaraki E, Koutsilieris M. Defects in insulin signaling pathways in ovarian steroidogenesis and other tissues in polycystic ovary syndrome (PCOS). J Steroid Biochem Mol Biol 2008;109:242-6.

33. Moghetti P, Castello R, Negri C, et al. Insulin infusion amplifies 17 alpha-hydroxycorticosteroid intermediates response to adrenocorticotropin in hyperandrogenic women: apparent relative impairment of 17,20-lyase activity. J Clin Endocrinol Metab 1996;81:881-6.

34. Yki-Järvinen $H$, Mäkimattila $S$, Utriainen $T$, Rutanen EM. Portal insulin concentrations rather than insulin sensitivity regulate serum sex hormone-binding globulin and insulin-like growth factor binding protein 1 in vivo. J Clin Endocrinol Metab 1995;80:3227-32.

35. Poretsky L, Cataldo NA, Rosenwaks Z, Giudice LC. The insulin-related ovarian regulatory system in health and disease. Endocr Rev 1999;20:535-82.

36. Gambineri A, Patton L, Altieri P, et al. Polycystic ovary syndrome is a risk factor for type 2 diabetes: results from a long-term prospective study. Diabetes 2012;61:2369-74.

37. Bremer AA, Miller WL. The serine phosphorylation hypothesis of polycystic ovary syndrome: a unifying mechanism for hyperandrogenemia and insulin resistance. Fertil Steril 2008;89:1039-48.

38. Corbould A, Kim YB, Youngren JF, et al. Insulin resistance in the skeletal muscle of women with PCOS involves intrinsic and acquired defects in insulin signaling. Am J Physiol Endocrinol Metab 2005;288:E1047-54.

39. Dunaif A, Segal KR, Futterweit W, Dobrjansky A. Profound peripheral insulin resistance, independent of obesity, in polycystic ovary syndrome. Diabetes 1989;38:1165-74.

40. Stepto NK, Cassar S, Joham AE, et al. Women with polycystic ovary syndrome have intrinsic insulin resistance on euglycaemic-hyperinsulaemic clamp. Hum Reprod 2013;28:777-84

41. Legro RS. Diabetes prevalence and risk factors in polycystic ovary syndrome. Obstet Gynecol Clin North Am 2001;28:99-109.

42. Dunaif A, Finegood DT. Beta-cell dysfunction independent of obesity and glucose intolerance in the polycystic ovary syndrome. J Clin Endocrinol Metab 1996;81:942-7.

43. Ehrmann DA, Kasza K, Azziz R, Legro RS, Ghazzi MN PCOS/Troglitazone Study Group. Effects of race and family history of type 2 diabetes on metabolic status of women with polycystic ovary syndrome. J Clin Endocrinol Metab 2005;90:66-71.

44. Dunaif A, Wu X, Lee A, Diamanti-Kandarakis E. Defects in insulin receptor signaling in vivo in the polycystic ovary syndrome (PCOS). Am J Physiol Endocrinol Metab 2001;281:E392-9.

45. Ciaraldi TP, Aroda V, Mudaliar S, Chang RJ, Henry RR. Polycystic ovary syndrome is associated with tissuespecific differences in insulin resistance. J Clin Endocrinol Metab 2009;94:157-63.

46. Ciaraldi TP. Molecular defects of insulin action in the polycystic ovary syndrome: possible tissue specificity. J Pediatr Endocrinol Metab 2000;13 Suppl 5:1291-3.

47. Ibáñez L, Sebastiani G, Diaz M, Gómez-Roig MD, LopezBermejo A, de Zegher F. Low body adiposity and high leptinemia in breast-fed infants born small-for-gestationalage. J Pediatr 2010;156:145-7.

48. Virtue S, Vidal-Puig A. It's not how fat you are, it's what you do with it that counts. PLoS Biol 2008;6:e237.

49. Virtue S, Vidal-Puig A. Adipose tissue expandability, lipotoxicity and the metabolic syndrome-an allostatic perspective. Biochim Biophys Acta 2010;1801:338-49.

50. Chazenbalk G, Trivax BS, Yildiz BO, et al. Regulation of adiponectin secretion by adipocytes in the polycystic ovary syndrome: role of tumor necrosis factor-\{alpha\}. J Clin 
Endocrinol Metab 2010;95:935-42.

51. Barber TM, Franks S. Adipocyte biology in polycystic ovary syndrome. Mol Cell Endocrinol 2013;373:68-76.

52. Padmanabhan V, Manikkam M, Recabarren S, Foster D. Prenatal testosterone excess programs reproductive and metabolic dysfunction in the female. Mol Cell Endocrinol 2006;246:165-74.

53. Dumesic DA, Schramm RD, Abbott DH. Early origins of polycystic ovary syndrome. Reprod Fertil Dev 2005;17:34960.

54. Legro RS, Bentley-Lewis R, Driscoll D, Wang SC, Dunaif A. Insulin resistance in the sisters of women with polycystic ovary syndrome: association with hyperandrogenemia rather than menstrual irregularity. J Clin Endocrinol Metab 2002;87:2128-33.

55. Hickey M, Sloboda DM, Atkinson HC, et al. The relationship between maternal and umbilical cord androgen levels and polycystic ovary syndrome in adolescence: a prospective cohort study. J Clin Endocrinol Metab 2009;94:3714-20.

56. Dumesic DA, Oberfield SE, Stener-Victorin E, Marshall JC, Laven JS, Legro RS. Scientific statement on the diagnostic criteria, epidemiology, pathophysiology, and molecular genetics of polycystic ovary syndrome. Endocr Rev 2015;36:487-525.

57. Hayes MG, Urbanek M, Ehrmann DA, et al. Genomewide association of polycystic ovary syndrome implicates alterations in gonadotropin secretion in European ancestry populations. Nat Commun 2015;6:7502.

58. Boomsma CM, Eijkemans MJ, Hughes EG, Visser GH, Fauser BC, Macklon NS. A meta-analysis of pregnancy outcomes in women with polycystic ovary syndrome. Hum Reprod Update 2006;12:673-83.

59. Weerakiet S, Srisombut C, Rojanasakul A, Panburana P, Thakkinstian A, Herabutya Y. Prevalence of gestational diabetes mellitus and pregnancy outcomes in Asian women with polycystic ovary syndrome. Gynecol Endocrinol 2004;19:134-40.

60. Qin JZ, Pang LH, Li MJ, Fan XJ, Huang RD, Chen HY. Obstetric complications in women with polycystic ovary syndrome: a systematic review and meta-analysis. Reprod Biol Endocrinol 2013;11:56.

61. Chittenden BG, Fullerton G, Maheshwari A, Bhattacharya S. Polycystic ovary syndrome and the risk of gynaecological cancer: a systematic review. Reprod Biomed Online 2009;19:398-405.

62. Haoula Z, Salman M, Atiomo W. Evaluating the association between endometrial cancer and polycystic ovary syndrome. Hum Reprod 2012;27:1327-31.

63. Timmermans A, Opmeer BC, Khan KS, et al. Endometrial thickness measurement for detecting endometrial cancer in women with postmenopausal bleeding: a systematic review and meta-analysis. Obstet Gynecol 2010;116:160-7.

64. Sartor BM, Dickey RP. Polycystic ovarian syndrome and the metabolic syndrome. Am J Med Sci 2005;330:336-42.

65. Colilla S, Cox NJ, Ehrmann DA. Heritability of insulin secretion and insulin action in women with polycystic ovary syndrome and their first degree relatives. J Clin Endocrinol Metab 2001;86:2027-31.

66. Legro RS, Gnatuk CL, Kunselman AR, Dunaif A. Changes in glucose tolerance over time in women with polycystic ovary syndrome: a controlled study. J Clin Endocrinol Metab 2005;90:3236-42.

67. Boudreaux MY, Talbott EO, Kip KE, Brooks MM, Witchel
SF. Risk of T2DM and impaired fasting glucose among PCOS subjects: results of an 8-year follow-up. Curr Diab Rep 2006;6:77-83.

68. Cheung LP, Ma RC, Lam PM, et al. Cardiovascular risks and metabolic syndrome in Hong Kong Chinese women with polycystic ovary syndrome. Hum Reprod 2008;23:1431-8.

69. Berneis K, Rizzo M, Lazzarini V, Fruzzetti F, Carmina E. Atherogenic lipoprotein phenotype and low-density lipoproteins size and subclasses in women with polycystic ovary syndrome. J Clin Endocrinol Metab 2007;92:1869.

70. Phelan N, O'Connor A, Kyaw-Tun T, et al. Lipoprotein subclass patterns in women with polycystic ovary syndrome (PCOS) compared with equally insulin-resistant women without PCOS. J Clin Endocrinol Metab 2010;95:3933-9.

71. Valkenburg O, Steegers-Theunissen RP, Smedts HP, et al. A more atherogenic serum lipoprotein profile is present in women with polycystic ovary syndrome: a case-control study. J Clin Endocrinol Metab 2008;93:470-6.

72. Isomaa $\mathrm{B}$, Almgren $\mathrm{P}$, Tuomi $\mathrm{T}$, et al. Cardiovascular morbidity and mortality associated with the metabolic syndrome. Diabetes Care 2001;24:683-9.

73. Weerakiet S, Bunnag P, Phakdeekitcharoen B, et al. Prevalence of the metabolic syndrome in Asian women with polycystic ovary syndrome: using the International Diabetes Federation criteria. Gynecol Endocrinol 2007;23:153-60.

74. Vgontzas AN, Legro RS, Bixler EO, Grayev A, Kales A, Chrousos GP. Polycystic ovary syndrome is associated with obstructive sleep apnea and daytime sleepiness: role of insulin resistance. J Clin Endocrinol Metab 2001;86:51720.

75. Gopal M, Duntley S, Uhles M, Attarian H. The role of obesity in the increased prevalence of obstructive sleep apnea syndrome in patients with polycystic ovarian syndrome. Sleep Med 2002;3:401-4.

76. Wild S, Pierpoint T, McKeigue P, Jacobs H. Cardiovascular disease in women with polycystic ovary syndrome at long-term follow-up: a retrospective cohort study. Clin Endocrinol (Oxf) 2000;52:595-600.

77. Lo JC, Feigenbaum SL, Yang J, Pressman AR, Selby JV, Go AS. Epidemiology and adverse cardiovascular risk profile of diagnosed polycystic ovary syndrome. J Clin Endocrinol Metab 2006;91:1357-63.

78. Cibula D, Cifkova R, Fanta M, Poledne R, Zivny J, Skibova $\mathrm{J}$. Increased risk of non-insulin dependent diabetes mellitus, arterial hypertension and coronary artery disease in perimenopausal women with a history of the polycystic ovary syndrome. Hum Reprod 2000;15:785-9.

79. Schmidt J, Landin-Wilhelmsen K, Brännström $M$, Dahlgren E. Cardiovascular disease and risk factors in PCOS women of postmenopausal age: a 21-year controlled follow-up study. J Clin Endocrinol Metab 2011;96:3794803.

80. Shroff R, Kerchner A, Maifeld M, Van Beek EJ, Jagasia D, Dokras A. Young obese women with polycystic ovary syndrome have evidence of early coronary atherosclerosis. J Clin Endocrinol Metab 2007;92:4609-14.

81. Luque-Ramirez M, Mendieta-Azcona C, Alvarez-Blasco F, Escobar-Morreale HF. Androgen excess is associated with the increased carotid intima-media thickness observed in young women with polycystic ovary syndrome. Hum Reprod 2007;22:3197-203. 
82. Talbott EO, Zborowski JV, Rager JR, Boudreaux MY, Edmundowicz DA, Guzick DS. Evidence for an association between metabolic cardiovascular syndrome and coronary and aortic calcification among women with polycystic ovary syndrome. J Clin Endocrinol Metab 2004;89:545461.

83. Boulman N, Levy $\mathrm{Y}$, Leiba $\mathrm{R}$, et al. Increased C-reactive protein levels in the polycystic ovary syndrome: a marker of cardiovascular disease. J Clin Endocrinol Metab 2004;89:2160-5.

84. Fauser BC, Tarlatzis BC, Rebar RW, et al. Consensus on women's health aspects of polycystic ovary syndrome (PCOS): the Amsterdam ESHRE/ASRM-Sponsored 3rd PCOS Consensus Workshop Group. Fertil Steril 2012;97:28-38.e25.

85. Johnstone EB, Rosen MP, Neril R, et al. The polycystic ovary post-rotterdam: a common, age-dependent finding in ovulatory women without metabolic significance. J Clin Endocrinol Metab 2010;95:4965-72.

86. Dewailly D, Lujan ME, Carmina E, et al. Definition and significance of polycystic ovarian morphology: a task force report from the Androgen Excess and Polycystic Ovary Syndrome Society. Hum Reprod Update 2014;20:334-52.

87. Quinn MM, Kao CN, Ahmad A, et al. Raising threshold for diagnosis of polycystic ovary syndrome excludes population of patients with metabolic risk. Fertil Steril 2016;106:1244-51.

88. Conway G, Dewailly D, Diamanti-Kandarakis E, et al. The polycystic ovary syndrome: a position statement from the European Society of Endocrinology. Eur J Endocrinol 2014;171:P1-29.

89. Moran LJ, Noakes M, Clifton PM, Tomlinson L, Galletly C, Norman RJ. Dietary composition in restoring reproductive and metabolic physiology in overweight women with polycystic ovary syndrome. J Clin Endocrinol Metab 2003;88:812-9.

90. Moran LJ, Hutchison SK, Norman RJ, Teede HJ. Lifestyle changes in women with polycystic ovary syndrome. Cochrane Database Syst Rev 2011;(7):CD007506.

91. Pasquali R, Gambineri A, Pagotto U. The impact of obesity on reproduction in women with polycystic ovary syndrome. BJOG 2006;113:1148-59.

92. Diamanti-Kandarakis E, Baillargeon JP, Iuorno MJ, Jakubowicz DJ, Nestler JE. A modern medical quandary: polycystic ovary syndrome, insulin resistance, and oral contraceptive pills. J Clin Endocrinol Metab 2003;88:192732.

93. World Health Organization. Medical eligibility criteria for contraceptive use. 2015. Available from: http://apps.who. int/iris/bitstream/10665/181468/1/9789241549158_eng. pdf. Accessed 10 Jul 2017.

94. The Faculty of Sexual and Reproductive Healthcare of the Royal College of Obstetricians and Gynaecologists (FSRH). FSRH Statement: Venous thromboembolism (VTE) and hormonal contraception Nov 2014. Available from: https:// www.fsrh.org/standards-and-guidance/documents/fsr hstatementvteandhormonalcontraception-november/. Accessed 10 Jul 2017.

95. National Institute for Health and Care Excellence. Fertility problems: assessment and treatment. 20 Feb 2013. Available from: https://www.nice.org.uk/guidance/cg156. Accessed 10 Jul 2017

96. Jayasena $\mathrm{CN}$, Franks S. The management of patients with polycystic ovary syndrome. Nat Rev Endocrinol 2014;10:624-36

97. Lord JM, Flight IH, Norman RJ. Metformin in polycystic ovary syndrome: systematic review and meta-analysis. BMJ 2003;327:951-3.

98. Legro RS, Barnhart HX, Schlaff WD, et al. Clomiphene, metformin, or both for infertility in the polycystic ovary syndrome. N Engl J Med 2007;356:551-66.

99. Moll E, van der Veen F, van Wely M. The role of metformin in polycystic ovary syndrome: a systematic review. Hum Reprod Update 2007;13:527-37.

100. Legro RS, Brzyski RG, Diamond MP, et al. Letrozole versus clomiphene for infertility in the polycystic ovary syndrome. N Engl J Med 2014;371:119-29.

101. Thessaloniki ESHRE/ASRM-Sponsored PCOS Consensus Workshop Group. Consensus on infertility treatment related to polycystic ovary syndrome. Hum Reprod 2008;23:462-77.

102. Kong GW, Cheung LP, Lok IH. Effects of laparoscopic ovarian drilling in treating infertile anovulatory polycystic ovarian syndrome patients with and without metabolic syndrome. Hong Kong Med J 2011;17:5-10.

103. Ma RC, Liu KH, Lam PM, et al. Sonographic measurement of mesenteric fat predicts presence of fatty liver among subjects with polycystic ovary syndrome. J Clin Endocrinol Metab 2011;96:799-807.

104. Naderpoor N, Shorakae S, de Courten B, Misso ML, Moran LJ, Teede HJ. Metformin and lifestyle modification in polycystic ovary syndrome: systematic review and metaanalysis. Hum Reprod Update 2015;21:560-74.

105. Skubleny D, Switzer NJ, Gill RS, et al. The impact of bariatric surgery on polycystic ovary syndrome: a systematic review and meta-analysis. Obes Surg 2016;26:169-76. 